$\left[\mathrm{C}_{5} \mathrm{HMe}_{4}\right] \mathrm{TiCl}_{2}^{+}$碎片, 说明 $\left[\mathrm{C}_{5} \mathrm{HMe}_{4}\right]_{2} \mathrm{TiCi}_{2}$ 中 $\mathrm{Ti}(\mathrm{IV})$ 与 $\left[\mathrm{C}_{5} \mathrm{HMe}_{4}\right]$ 间的键较弱, 容易 被击开.

$\left[\mathrm{C}_{5} \mathrm{HMe}_{4}\right]_{2} \mathrm{TiCl}_{2}$ 的 ${ }^{1} \mathrm{H}$ NMR 谱共有三 个峰, 按化学位移由大到小为序其积分强度 比为 $1: 6: 6$, 恰好与配位体 $\left[\mathrm{C}_{5} \mathrm{HMe}_{4}\right]$ 上的 三种 $\mathrm{H}$ 相对应, - - - 种为环上 $\mathrm{C}$ 原子上直接相 连的 $\mathrm{H}(\delta-5.99)$, 另外两种为 $\mathrm{CH}_{3}$ 上的 $\mathrm{H}(\delta-2.04,1.89)$. 由于 'H NMR 谱上只 有三个峰, 说明 $\left[\mathrm{C}_{5} \mathrm{HMe}_{4}\right]_{2} \mathrm{TiCl}_{2}$ 分子中的 两个 $\left[\mathrm{C}_{5} \mathrm{HMe}_{4}\right]$ 是等价的, 该分子存在两个
相互垂直的对称面, 呈覆盖型 结构. 文 献中报道过 $\left[\mathrm{C}_{5} \mathrm{H}_{5}\right]_{2} \mathrm{TiCl}_{2}$ 为交错型结构, $\left[\mathrm{C}_{5} \mathrm{Me}_{5}\right]_{2} \mathrm{TiCl}_{2}$ 为覆盖型结构, 而 $\left[\mathrm{C}_{5} \mathrm{H}_{3} \mathrm{R}_{2}\right]_{2}$ $\mathrm{TiCl}_{2}\left(\mathrm{R}=\mathrm{C}\left(\mathrm{CH}_{3}\right)_{3}\right)$ 为介于交错和覆盖型 之间的结构. 由此可知双- $\boldsymbol{\eta}$-环戊二烯基钛 体系化合物的结构与环 戊二烯基的取 代 情况有关. $\left[\mathrm{C}_{5} \mathrm{HMe}_{4}\right]_{2} \mathrm{Fe}$ 为交错型结构, $\left[\mathrm{C}_{5} \mathrm{HMe}_{4}\right]_{2} \mathrm{Ru}$ 为覆盖型结构, 说明夹心化合 物的结构与过渡金属元素有关.

\section{王悦 梁映秋}

(吉林大学理论化学研究所, 长春 130623)

\title{
一类“非季铵型重活化剂”的构效关系研究“
}

Bedford 等曾报道了一类对位取代苯 基- $\boldsymbol{\alpha}$-羰基硫代羟肜酸-二烃胺基硫醇酯（4$\left.\mathrm{RC}_{6} \mathrm{H}_{4}-\mathrm{COC}(\mathrm{NOH})-\mathrm{S}-\left(\mathrm{CH}_{2}\right)_{n}-\mathrm{NR}^{\prime} \mathrm{R}^{\prime \prime}\right)$ 的 结构及其体外重活化作用, 并讨论了该类化 合物肟羟基解离度、取代基的 Hammitt 常 数等与重活化作用的构效关系. 根据经典重 活化理论, 作者将其看成为“非季铵型重活化 剂”.

我们对该类药物进行了分子力学和量子 化学计算, 通过比较季铵和“非季铵类”重活 化剂的构效关系及其药物分子的总体性质, 得到一些新的重要结果.

1. “非季铵重活化剂”只有在成盐之后才 能表现重活化作用，可见二烃胺基也是重活 化基团之一. 因为二烃胺基成盐之后能与胆 碱酯酶活性中心附近的负性部位密切结合, 季铵径更增强了电荷作用, 所以均比相应的 .非季铵盐重活化率高.

2. $\mathrm{R}^{\prime}$ 为二乙胺基时优于二甲胺基, 可能
是空间因素和色散力影响的结果.

3. 苯环上对位取代基 $\mathrm{R}$ 的拉电子性增强 可使重活化率相应升高, 典型推电子团使重 活化率降低. 量子化学计算表明, 拉电子取 代基能使药物分子的最低空轨道能 (LUMO) 降低, 随着 LUMO 的降低, 其重活化率相应 升高. 在这一点上季铵和非季铵重活化剂的 规律基本一致. 由此推测, 重活化作用发生 时可能伴随分子轨道作用. 因此, 我们认为 该类化合物的芳香环也是重活化剂的重要组 成部分. 根据我们的重活化理论, 如果将取 代的苯环改为其它芳稠环或芳杂环, 可能会 取得更好的效果。由此设计出一类可能会成 为叔胺型重活化剂的基本结构通式, 并在嘌 呤类药物合成中取得一定预想结果.

焦克芳宋鸿镂卜志洁

(军事医学科学院药理毒理研究所, 北京 100850)

*国家自然科学基金资助项目

\section{杂多化合物对蛋鸡的生理作用的研究}

杂阴离子体积大, 电荷密度小,在水和含

第 22 期
科学通报 氧有机溶剂中溶解度大, 对细胞膜和原生质 